\title{
Effect of nitrogen sources on the activities of lipogenic enzymes in oleaginous fungus Cunninghamella echinulata
}

\author{
Milan Certik, ${ }^{*, \dagger}$ Jana Megova, ${ }^{1}$ and Robert Horenitzky ${ }^{2}$ \\ Department of Biochemical Technology, Faculty of Chemical Technology, Slovak Technical University, \\ Radlinskeho 9, 81237 Bratislava, Slovak Republic \\ ${ }^{1}$ Department of Biochemistry, Faculty of Natural Sciences, Komenius University, Mlynska dolina, 84215 Bratislava, Slovak Republic \\ ${ }^{2}$ LIKO Research Institute, Mileticova 23, 82006 Bratislava, Slovak Republic
}

(Received July 16, 1999; Accepted November 12, 1999)

\begin{abstract}
Various inorganic and organic nitrogen sources were used to compare their effects on the lipogenesis and the activities of lipogenic enzymes (providing acetyl-CoA and donating NADPH) in $\gamma$ linolenic acid-producing fungus Cunninghamella echinulata. Lipid accumulation was enhanced by organic nitrogen, among them the presence of corn-steep led to almost $40 \%$ oil in the biomass. While organic nitrogen increased activities of acetyl-CoA carboxylase (ACC) and malic enzyme (ME), ATP:citrate lyase (ACL) was rapidly enhanced by ammonium ion. The use of $\mathrm{NaNO}_{3}$ resulted in high activities of glucose 6-phosphate dehydrogenase (GPD) and 6-phosphogluconate dehydrogenase (PGD). NADP-isocitrate dehydrogenase (NADP-ICD) was more active when the fungus utilized all inorganic $\mathrm{N}$-compounds. The rise of nitrogen concentration in medium was accompanied with reduced lipid accumulation and a fall of ACL, ACC, and ME. In contrast, N-sufficient conditions favored biomass growth and elevated activities of GPD and PGD. Kinetic experiments also suggest that a significant portion of the required acetyl-CoA was being provided via $A C L$ and $A C C$, and ME (probably coupled with GPD) channeled the NADPH into the fatty acid biosynthesis. The contribution of the lipogenic enzymes to metabolic pathways other than lipogenesis is also discussed.
\end{abstract}

Key Words_—lipid accumulation; lipogenic enzymes; nitrogen source; oleaginous fungi

All microorganisms are able to synthesize lipids for essential functioning of their membranous structures. However, a few microbes in microbial kingdom accumulate more than $20 \%$ lipids in their cells. These organisms, so called oleaginous, store lipid in oil vacuoles in the form of triacylglycerols. Some of these microbial oils have a great potential value because they are composed of commercially interesting and healthy important polyunsaturated fatty acids (Certik and Shimizu, 1999a, b).

The basic physiology of lipid overproduction is that the organism is cultivated on a medium consisting of a carbon source excess and a limited quantity of other important nutrients, especially nitrogen. The definition

\footnotetext{
* Address reprint requests to: Dr. Milan Certik, Department of Biochemical Technology, Faculty of Chemical Technology, Slovak Technical University, Radlinskeho 9, 81237 Bratislava, Slovak Republic.

${ }^{\dagger}$ Present address: Division of Applied Life Sciences, Graduate School of Agriculture, Kyoto University, Sakyo-ku, Kyoto 606-8502, Japan.

E-mail: mcertik@yahoo.com
}

of the lipid accumulation mechanism in oleaginous microorganisms is based on the possession of one of the key enzymes of lipogenesis, namely, ATP:citrate lyase (ACL), which provides acetyl-CoA by the cleaving of citrate (Botham and Ratledge, 1979). Microorganisms without this enzyme appear to be unable to achieve the same degree of lipid accumulation as those that possess it. The initial and rate-limiting step of fatty acid biosynthesis, catalyzed by acetyl-CoA carboxylase (ACC), is the ATP-dependent conversion of acetyl-CoA to malonyl-CoA, the two-carbon donor for fatty acid chain extension. In yeasts, it was proposed that ACC is also involved in the elongation of very long-chain fatty acids (Schneiter et al., 1996). Simultaneously, the formation of the reducing power (NADPH) essential for the conversion of the acetylCoA into fatty acids must be provided. Several pathways produce NADPH in cells growing on glucose. It is generated primarily via the oxidation of glucose 6phosphate in the pentose phosphate cycle by glucose 6-phosphate dehydrogenase (GPD) and 6-phospho- 
gluconate dehydrogenase (PGD). Malic enzyme (ME) was shown to be an important source of NADPH for lipid accumulation in oleaginous yeasts (Evans and Ratledge, 1985) and fungi (Wynn and Ratledge, 1997; Wynn et al., 1997) as well as for fungal fatty acid desaturation reactions (Kendrick and Ratledge, 1992). However, the oxidation of cytosolic isocitrate by NADP-isocitrate dehydrogenase (NADP-ICD) also contributed to NADPH generation in lipid-accumulating yeasts (Sokolov et al., 1995).

Although lipogenesis comprises all metabolic steps from glucose to triacylglycerols, attention has mostly focused on the enzymes that catalyze the formation of a two-carbon precursor for fatty acid synthesis and on the auxiliary systems donating NADPH. It is more than likely that more than one pathway may be engaged in this process, and which pathway is used varies with the developmental stage, cultivation condition, and microbial species. The nature and concentration of nitrogen source used in the medium is an essential factor regulating lipogenesis. Many reports have been made about various nitrogen sources employed for fungal fatty acid production (Certik et al., 1993a; Kolesnikova and Tolstikova, 1984; Moreton, 1988). However, information on how these compounds influence the activity of lipogenic enzymes is limited. This information would quantify the drain of precursors from the central carbon metabolism to lipid biosynthesis together with the requirements for cofactors such as NADPH, and it is also important for the optimization of a fermentation process. Therefore this paper deals with the effect of several nitrogen sources on the activities of enzymes that may be engaged in the initial stage of lipid accumulation in oleaginous fungus Cunninghamella echinulata CCF-103, the producer of biologically active $\gamma$ linolenic acid (Certik et al., 1993b).

\section{Materials and Methods}

Cultivation condition. The strain C. echinulata CCF-103 was cultivated in two types of medium. Modified semisynthetic Czapek-Dox medium contained $(\mathrm{g} / \mathrm{L})$ : glucose $50, \mathrm{~N}$-source 0.5 , yeast extract 5 , $\mathrm{K}_{2} \mathrm{HPO}_{4} 1.5, \mathrm{MgSO}_{4} \cdot 7 \mathrm{H}_{2} \mathrm{O} 1, \mathrm{KCl} 0.5, \mathrm{FeSO}_{4} \cdot 7 \mathrm{H}_{2} \mathrm{O}$ 0.01 , and distilled water. As $\mathrm{N}$-sources were used (g/L): $\mathrm{NH}_{4} \mathrm{Cl}$ 1.9, $\left(\mathrm{NH}_{4}\right)_{2} \mathrm{SO}_{4}$ 2.4, $\left(\mathrm{NH}_{4}\right)_{2} \mathrm{HPO}_{4} 2.4$, $\mathrm{NH}_{4} \mathrm{NO}_{3}$ 2.9, $\mathrm{NaNO}_{3} 3.0$, lysine $\cdot \mathrm{HCl} 3.3$, urea 1.1, alanine 3.2, glutamine 2.6, glutamate 5.2, and a mixture of amino acids $(14.19 \% \mathrm{~N}$; Bacto Casamino Acids, Difco, Detroid, MI, USA) 3.5. When $\left(\mathrm{NH}_{4}\right)_{2} \mathrm{HPO}_{4}$ was employed as an $\mathrm{N}$-source, $\mathrm{K}_{2} \mathrm{HPO}_{4}$ was not added. In experiments with various $\mathrm{N}$ concentrations $(0.1,0.3,0.5,0.7,1.0$, and $1.2 \mathrm{~g} / \mathrm{L})$, an appropriate amount of $\mathrm{NaNO}_{3}$ was used. The $\mathrm{pH}$ was adjusted by the addition of $1 \mathrm{~m} \mathrm{NaOH}$ at a value of 6.0 , and $\mathrm{CaCO}_{3}$
( $0.2 \mathrm{~g}$ per flask) was employed to maintain $\mathrm{pH}$ during cultivation. The other medium was composed of $(\mathrm{g} / \mathrm{L})$ : glucose $50 \mathrm{~g}$, an appropriate amount of corn-steep (6.64\% $\mathrm{N} / \mathrm{dry}$ corn-steep) at a final $\mathrm{N}$ concentration $0.1,0.3,0.5,0.7,1.0$, and $1.2 \mathrm{~g} \mathrm{~N}$, and distilled water. The $\mathrm{pH}$ was adjusted by the addition of $1 \mathrm{M} \mathrm{NaOH}$ at a value of 6.0 . All $500 \mathrm{ml}$ cultivation flasks (equipped with buffles to improve aeration) containing $100 \mathrm{ml}$ of medium were inoculated with the spore suspension in an isotonic solution at a final concentration of $1-2 \times 10^{6}$ spores per $\mathrm{ml}$ and incubated on a rotary shaker $(150 \mathrm{rpm})$ for $1-7$ days at $28^{\circ} \mathrm{C}$. All cultivation experiments were performed at triplicates and analyzed individually.

Enzyme assays. Cells after cultivation were harvested by vacuum filtration, washed twice with $50 \mathrm{~mm}$ $\mathrm{KH}_{2} \mathrm{PO}_{4} / \mathrm{Na}_{2} \mathrm{PO}_{4}$ buffer $(\mathrm{pH} 7.3)$, and filtered again. The fungus was then resuspended in an appropriate buffer ( $4 \mathrm{ml}$ buffer per $1 \mathrm{~g}$ wet biomass) according to the relevant assay method (see below) and disrupted by a knife homogenizer at $+4^{\circ} \mathrm{C}$. Homogenized mycelium was centrifuged at $1,500 \times \mathrm{g}$ for $5 \mathrm{~min}$ at $+4^{\circ} \mathrm{C}$ to remove whole cells, debris, and nuclei. Supernatant was centrifuged again at $20,000 \times g$ for 30 min at $+4^{\circ} \mathrm{C}$. The determination of individual enzyme activities was performed in the resultant supernatant fraction by the following methods: ACL (EC 4.1.3.8) (Srere, 1962), ACC (EC 6.4.1.2) (Morrice et al., 1998), ME (malate dehydrogenase decarboxylating; EC 1.1.1.40) (Ochoa, 1955), GPD (EC 1.1.1.49) (Kuby and Noltmann, 1966), PGD (EC 1.1.1.44) (Pontremoli and Grazi, 1966), and NADP-ICD (EC 1.1.1.42) (Kornberg, 1955). At least three measurements for each enzyme activity were carried out to assess reproducibility.

Lipid isolation, fatty acid analysis, and other methods. Total lipid was extracted from dry mycelium with chloroform/methanol $(2: 1, \mathrm{v} / \mathrm{v})$ according to Certik et al. (1996). Fatty acids from total lipids were released by alkaline hydrolysis (refluxing with $1 \mathrm{M} \mathrm{KOH}$ in $95 \%$ ethanol for $1 \mathrm{~h}$ ) and converted into their methylesters (Christoperson and Glass, 1969). Fatty acid methylesters were analyzed by gas chromatography as we described previously (Sajbidor et al., 1994). Protein concentration was carried out by using the method of Lowry et al. (1951) with bovine serum albumin as a standard. Glucose concentration in media was estimated by the method of Miller (1959).

\section{Results and Discussion}

In oleaginous microbes, as C. echinulata CCF-103, a sufficient conversion of carbon to lipid would be expected. Our experiments show that although inorganic $\mathrm{N}$-sources in medium resulted in high growth and low 
Table 1. Growth, lipid accumulation in biomass, $\gamma$-linolenic acid production, and activities of lipogenic enzymes in C. echinulata cultivated on various $\mathrm{N}$-sources $(0.5 \mathrm{~g} \mathrm{~N} / \mathrm{L})$ at $28^{\circ} \mathrm{C}$ for 4 days.

\begin{tabular}{|c|c|c|c|c|c|c|c|c|c|c|}
\hline \multirow{2}{*}{$\mathrm{N}$-source } & \multirow{2}{*}{$\begin{array}{c}\mathrm{DCW}^{a} \\
(\mathrm{~g} / \mathrm{L})\end{array}$} & \multirow{2}{*}{$\begin{array}{l}\text { TL/DCW } \\
(\%, w / w)\end{array}$} & \multicolumn{2}{|c|}{$\mathrm{GLA}^{c}$} & \multicolumn{6}{|c|}{ Enzyme specific activity (nmol/min $\mathrm{mg}$ ) } \\
\hline & & & (\% in oil, w/w) & $(\mathrm{mg} / \mathrm{L})$ & ACL & $\mathrm{ACC}$ & ME & $I C D$ & GPD & PGD \\
\hline $\mathrm{NaNO}_{3}$ & 17.6 & 12.6 & 19.1 & 342 & 12.6 & 15.3 & 44.8 & 34.2 & 226.7 & 283.0 \\
\hline $\mathrm{NH}_{4} \mathrm{NO}_{3}$ & 18.2 & 11.1 & 18.1 & 292 & 50.2 & 11.2 & 39.1 & 32.9 & 153.0 & 204.4 \\
\hline$\left(\mathrm{NH}_{4}\right)_{2} \mathrm{SO}_{4}$ & 16.2 & 9.8 & 14.0 & 176 & 65.7 & 13.2 & 19.5 & 38.3 & 66.5 & 72.1 \\
\hline$\left(\mathrm{NH}_{4}\right)_{2} \mathrm{HPO}_{4}$ & 17.3 & 8.1 & 16.2 & 176 & 62.9 & 10.0 & 18.3 & 25.2 & 84.9 & 86.8 \\
\hline $\mathrm{NH}_{4} \mathrm{Cl}$ & 16.7 & 11.3 & 15.9 & 240 & 60.7 & 12.8 & 20.0 & 35.8 & 70.6 & 70.8 \\
\hline Lysine & 13.6 & 18.2 & 18.2 & 377 & 12.6 & 22.0 & 64.8 & 12.5 & 75.0 & 83.3 \\
\hline Urea & 11.1 & 15.1 & 18.6 & 257 & 10.1 & 16.7 & 69.6 & 13.0 & 40.9 & 52.0 \\
\hline Alanine & 12.4 & 25.6 & 14.7 & 403 & 12.6 & 28.3 & 80.2 & 10.0 & 61.1 & 70.2 \\
\hline Glutamine & 13.3 & 21.3 & 15.7 & 378 & 12.5 & 24.0 & 73.7 & 8.1 & 83.0 & 81.7 \\
\hline Glutamate & 14.8 & 18.4 & 16.5 & 377 & 9.5 & 22.4 & 74.0 & 10.6 & 102.0 & 104.4 \\
\hline Casamino $^{d}$ & 12.2 & 29.7 & 14.1 & 450 & 14.8 & 39.4 & 103.6 & 9.3 & 82.4 & 94.5 \\
\hline Corn-steep & 11.8 & 33.0 & 13.4 & 460 & 15.9 & 43.5 & 112.4 & 5.3 & 71.0 & 128.0 \\
\hline
\end{tabular}

${ }^{a}$ DCW: dry cell weight (biomass).

${ }^{b}$ TL/DCW: total lipid per dry cell weight.

${ }^{c}$ GLA: $\gamma$-linolenic acid.

${ }^{d}$ Mixture of amino acids (Bacto Casamino Acids).

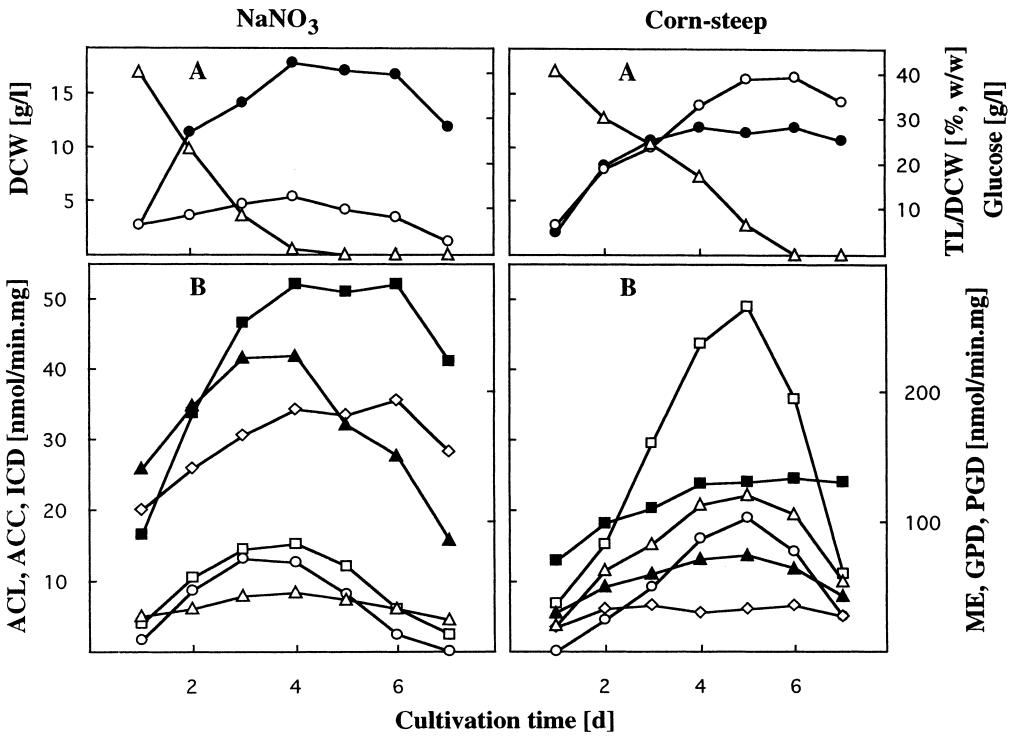

Fig. 1. Kinetic experiments of $C$. echinulata cultivated at the presence of $\mathrm{NaNO}_{3}$ and corn-steep at $28^{\circ} \mathrm{C}$.

A. ๑, biomass (DCW—dry cell weight); $\bigcirc$, lipid accumulation (TL/DCW); $\triangle$, glucose consumption. B. Enzyme activities: $\bigcirc$, ACL; $\square$, ACC; $\triangle$, ME; $\diamond$, NADP-ICD; $\mathbf{\square}$, GPD; $\boldsymbol{\Delta}$, PGD.

lipid formation, increased oil accumulation was connected with the use of organic nitrogen (Table 1). Because the content of $\gamma$-linolenic acid varied from 13 to $19 \%$, its total yield (176-460 mg/L) depended on the fungal ability to synthesize and accumulate intracellular oil. Since $C$. echinulata is thought to be used for the production of this fatty acid (Certik and Horenitzky, 1999), the activities of the enzymes, which could be involved in the initial phase of lipid formation, were further investigated. It is interesting that although $\mathrm{ACL}$ was rapidly enhanced at the presence of ammonium ion [probably because of elevated affinity of the en- zyme for its substrate, citrate (Evans and Ratledge, 1985)], the lipid content in biomass remained low. On the other hand, an increase of ACC activity was accompanied with the use of organic nitrogen and closely paralleled the rise of lipid accumulation (Table 1). However, the close relationship of $A C L$ and $A C C$ to the rate of fatty acid biosynthesis in $C$. echinulata grown either on $\mathrm{NaNO}_{3}$ or corn-steep (Fig. 1) prove that a significant portion of the required acetyl-CoA was being provided via these enzymes. Moreover, the change of metabolic priorities from $\mathrm{N}$-sufficient to $\mathrm{N}$ limited conditions was accompanied with high lipid ac- 


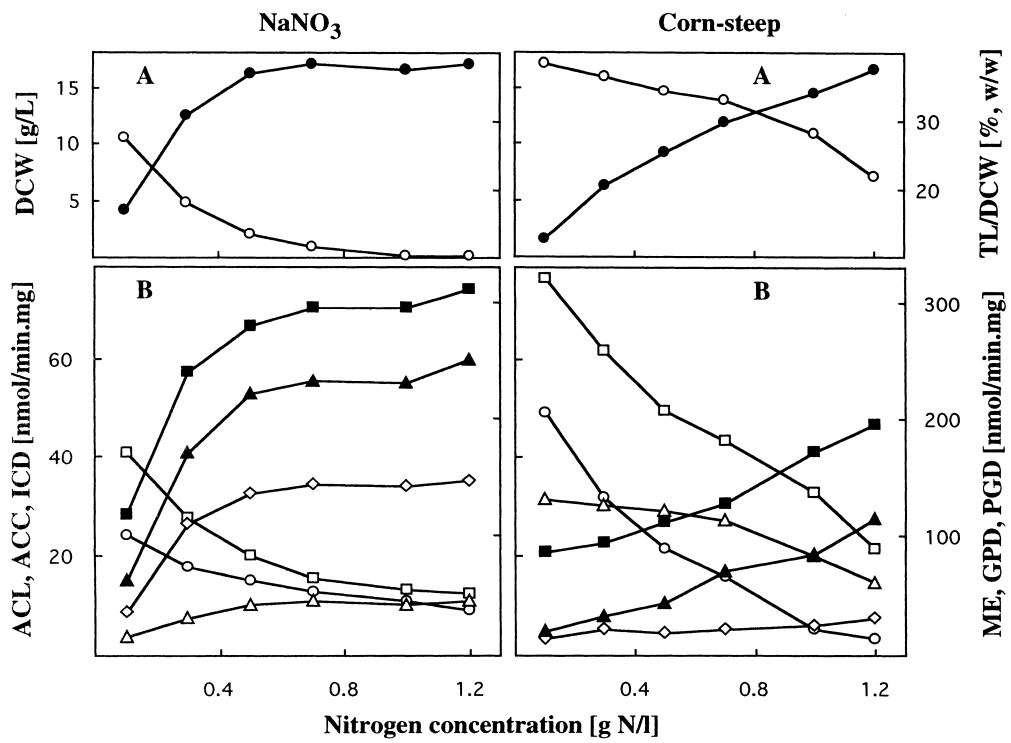

Fig. 2. Effect of nitrogen concentration on the growth, lipid accumulation, and enzyme activities of $C$. echinulata cultivated in the presence of $\mathrm{NaNO}_{3}$ and corn-steep at $28^{\circ} \mathrm{C}$ for 4 days.

A. ๑, biomass (DCW-dry cell weight); $\bigcirc$, lipid accumulation (TL/DCW). B. Enzyme activities: $\bigcirc, A C L ; \square, A C C ; \triangle, M E ; \diamond$, NADP-ICD; $\mathbf{\square}$, GPD; $\boldsymbol{\Lambda}$, PGD.

cumulation in the fungal cells $\left(27.5 \%\right.$ for $\mathrm{NaNO}_{3}$ and $38.4 \%$ for corn-steep) and with rapid increase of both ACL and ACC activities (Fig. 2). Together, this indicates that although the presence of $A C L$ is necessary for the synthesis of acyl-CoA by cleaving citrate (Botham and Ratledge, 1979), a high degree of oleaginicity depends on the rate of $A C C$ by which the acetyl-CoA is efficiently converted to malonyl-CoA. Thus the regulation of ACC might be a critical step in reaching high lipid overproduction in $C$. echinulata. However, by which mechanism organic nitrogen enhances the ATP-dependent conversion of acetyl-CoA to malonyl-CoA catalyzed by ACC remains to be answered.

Although the availability of acetyl-CoA and its subsequent conversion to fatty acids is important, an adequate supply of NADPH is a crucial requirement to maintain the process. The rapidly increased ME activity at the presence of organic nitrogen and the close relationship among $\mathrm{ACC}, \mathrm{ME}$, and lipid accumulation (Table 1, Fig. 1) imply that ME is tightly bound with lipid synthesis in $C$. echinulata and channels the reducing power into the condensation reaction of acetylCoA to yield fatty acids. ME was also detected as a major source of NADPH for de novo lipid biosynthesis in other fungi (Wynn and Ratledge, 1997; Wynn et al., 1997) and yeasts (Evans and Ratledge, 1985). It is noteworthy that although Table 1 and Fig. 2 show no correlation between GPD and ME, GPD activities follow the rate of overall lipid accumulation during kinetic experiments and are similar to those of $\mathrm{ME}, \mathrm{ACL}$, and ACC activities (Fig. 1). It may evoke possible function- al linkage of GPD with ME, where GPD may subsidize the flow of NADPH to fatty acid biosynthetic machinery. How this cooperation is triggered and regulated is the subject of our further studies.

A rise in the activities of GPD, PGD, and NADP-ICD with increasing nitrogen concentration (Fig. 2) was obviously due to glucose incorporation into various metabolic pathways and substantial inquiry for NADPH during the high cell division and total biomass growth. Thus a lowering of lipid overproduction under $\mathrm{N}$-sufficient conditions was a plausible consequence of reduced availability of adequate metabolites and cofactors for lipogenesis, and fatty acids were synthesized as "metabolic active" lipid for essential functioning of the fungal membranous structures.

Because lipid accumulation at the presence of $\mathrm{NaNO}_{3}$ was not as high as with the use of organic $\mathrm{N}$ compounds (but the best among all inorganic $\mathrm{N}$ sources), the increased activities of some NADP-producing dehydrogenases at the presence of $\mathrm{NaNO}_{3}$ suggest that these enzymes are involved more or less in other metabolic pathways, which in turn depend on the nature and concentration of nitrogen source used in the medium. To our knowledge, the relationship between $\mathrm{NO}_{3}{ }^{-}$and lipid biosynthesis has not yet been studied in oleaginous microorganisms. Several factors should be taken into account: a) transport of $\mathrm{NO}_{3}{ }^{-}$ through cytoplasmic membrane, b) different valence state of $\mathrm{NO}_{3}^{-}$, and c) conversion and reduction of $\mathrm{NO}_{3}{ }^{-}$into $\mathrm{NH}_{4}{ }^{+}$. Thus the increased ME activity by $\mathrm{NaNO}_{3}$ might be connected, besides its contribution to fatty acid synthesis, with the reduction of nitrate to 
ammonium ion, as it was found in Fusarium oxysporum (Zink and Katz, 1973). Moreover, distinctly high activities of GPD and PGD caused by growth of the fungus on oxidized nitrogen (Table 1) may be a widespread phenomenon, indicating that these dehydrogenases are responsible to meet the demand for $\mathrm{NADPH}$ when the strain utilizes $\mathrm{NaNO}_{3}$. Similar results were also reported for Aspergillus nidulans (Singh et al., 1988). On the other hand, enhanced activities of NADP-ICD by inorganic nitrogen (Table 1) and its changes during the fungal growth (Figs. 1 and 2) suggest its possible connection with biomass production at the presence of inorganic nitrogen instead of at the presence of the organic one.

In conclusion, of the enzymes investigated in $C$. echinulata, ACL and ACC are triggers for lipid overproduction by providing and maintaining the flux of a two-carbon donor for lipid accumulation. ME probably coupled with GPD donates NADPH for fatty acid synthesis, but depending on the nitrogen nature they also contribute more or less to other metabolic pathways. It would be necessary to keep the key lipogenic enzymes at constantly high activities to ensure sufficient lipid accumulation in this fungus, the producer of essential $\gamma$-linolenic acid. Present work demonstrates that the chemical composition and concentration of nitrogen source in medium is as a means of physiological control and regulation of lipid metabolism, and it provides information that pathways are active under these conditions in C. echinulata.

\section{References}

Botham, P. A. and Ratledge, C. (1979) A biochemical explanation for lipid accumulation in Candida 107 and other oleaginous micro-organisms. J. Gen. Microbiol., 114, 361-375.

Certik, M., Andrasi, P., and Sajbidor, J. (1996) Effect of extraction methods on lipid yield and fatty acid composition of lipid classes containing $\gamma$-linolenic acid extracted from fungi. J. Am. Oil Chem. Soc., 73, 357-365.

Certik, M. and Horenitzky, R. (1999) Supercritical $\mathrm{CO}_{2}$ extraction of fungal oil containing $\gamma$-linolenic acid. Biotechnol. Tech., 13, 1115.

Certik, M., Sajbidor, J., and Stredanska, S. (1993a) Effect of carbon and nitrogen sources on growth, lipid production and fatty acid composition of Mucor mucedo F-1384. Microbios, 74, 7-15.

Certik, M., Sereke Berhan, S., and Sajbidor, J. (1993b) Lipid production and fatty acid composition of selected strains belonging to Mucorales. Acta Biotechnol., 13, 193-196.

Certik, M. and Shimizu, S. (1999a) Biosynthesis and regulation of microbial polyunsaturated fatty acid production. J. Biosci. Bioeng., 87, 1-14.

Certik, M. and Shimizu, S (1999b) Production and application of single cell oils. Agro Food Ind. Hi-Tech., 10, 26-32.

Christoperson, S. W. and Glass, R. L. (1969) Preparation of milk fat methyl esters by alcoholysis in an essentially nonalcoholic solu- tion. J. Dairy Sci., 52, 1289-1290.

Evans, C. T. and Ratledge, C. (1985) Possible regulatory roles of ATP:citrate lyase, malic enzyme and AMP deaminase in lipid accumulation by Rhodosporidium toruloides CBS 14. Can. J. Microbiol., 31, 1000-1005.

Kendrick, A. and Ratledge, C. (1992) Desaturation of polyunsaturated fatty acids in Mucor circinelloides and the involvement of a novel membrane-bound malic enzyme. Eur. J. Biochem., 209, 667-673.

Kolesnikova, I. G. and Tolstikova, G. V. (1984) Fatty acid composition of lipids from Aspergillus fungi grown on media with different nitrogen sources. Mikrobiologyia, 53, 826-829.

Kornberg, A. (1955) Isocitric dehydrogenase of yeast. In Methods in Enzymology, Vol. 1, ed. by Colowick, S. P. and Kaplan, N. O., Academic Press, New York, pp. 705-709.

Kuby, S. A. and Noltmann, E. A. (1966) Glucose 6-phosphate dehydrogenase (crystalline) from brewers' yeast. In Methods in Enzymology, Vol. 9, ed. by Colowick, S. P. and Kaplan, N. O., Academic Press, New York, pp. 116-125.

Lowry, O. H., Rosebrough, N. J., Farr, A. L., and Randall, R. J. (1951) Protein measurement with the folin phenol reagent. J. Biol. Chem., 193, 265-275.

Miller, G. L. (1959) Use of dinitrosalicylic acid reagent for determination of reducing sugar. Anal. Chem., 31, 426-428.

Moreton, R. S. (1988) Physiology of lipid accumulating yeasts. In Single Cell Oil, ed. by Moreton, R. S., Longman Scientific \& Technical, Harlow, pp. 1-32.

Morrice, J., MacKenzie, D. A., Parr, A. J., and Archer, D. B. (1998) Isolation and characterisation of the acetyl-CoA carboxylase gene from Aspergillus nidulans. Curr. Genet., 34, 379-385.

Ochoa, S. (1955) "Malic" enzyme. In Methods in Enzymology, Vol. 1, ed. by Colowick, S. P. and Kaplan, N. O., Academic Press, New York, pp. 739-753.

Pontremoli, S. and Grazi, E. (1966) 6-Phosphogluconate dehydrogenase-Crystalline. In Methods in Enzymology, Vol. 9, ed. by Colowick, S. P. and Kaplan, N. O., Academic Press, New York, pp. 137-141.

Sajbidor, J., Certik, M., and Grego, J. (1994) Lipid analysis of baker's yeasts. J. Chromatogr., 665, 191-195.

Schneiter, R., Hitomi, M., Ivessa, A. S., Fasch, E.-V., Kohlwein, S. D., and Tartakoff, A. M. (1996) A yeast acetyl coenzyme A carboxylase mutant links very-long-chain fatty acid synthesis to the structure and function of the nuclear membrane-pore complex. Mol. Cell. Biol., 16, 7161-7172.

Singh, M., Scrutton, N. S., and Scrutton, M. C. (1988) NADP generation in Aspergillus nidualns: Is the mannitol cycle involved? J. Gen. Microbiol., 134, 643-654.

Sokolov, D. M., Sharyshev, A. A., and Finogenova, T. V. (1995) Subcellular location of enzymes mediating glucose metabolism in various groups of yeasts. Biochemistry (Moscow), 60, $1325-1331$.

Srere, P. A. (1962) Citrate-cleavage enzyme. In Methods in Enzymology, Vol. 5, ed. by Colowick, S. P. and Kaplan, N. O., Academic Press, New York, pp. 641-644.

Wynn, J. P., Kendrick, A., and Ratledge, C. (1997) Sesamol as an inhibitor of growth and lipid metabolism in Mucor circinelloides via its action on malic enzyme. Lipids, 32, 605-610.

Wynn, J. P. and Ratledge, C. (1997) Malic enzyme is a major source of NADPH for lipid accumulation by Aspergillus nidulans. Microbiology, 143, 253-257.

Zink, M. W. and Katz, J. S. (1973) Malic enzyme of Fusarium oxysporum. Can. J. Microbiol., 19, 1187-1196. 